\title{
Is Carry Trade Still Profitable in Turkish Lira?
}

\author{
Aykut Akdağ ${ }^{1}$ \\ ${ }^{1}$ Department of Business Administration, Yeni Yüzyıl University, Istanbul, Turkey \\ Correspondence: Aykut Akdağ, Department of Business Administration, Faculty of Economics and Administrative \\ Sciences, Yeni Yüzyll University, Istanbul, Turkey.
}

Received: October 28, 2016

Accepted: November 11, $2016 \quad$ Online Published: December 8, 2016

doi:10.5430/ijfr.v8n1p26

URL: http://dx.doi.org/10.5430/ijfr.v8n1p26

\begin{abstract}
Carry trades are basically trades to take the advantage of high interest rates in one country by borrowing in a low interest country. The major risk in this type of financial investment is the currency risk. During the carry trade, the depreciation of the high interest rate currency against the low interest currency has to be avoided to protect carry trade profits, and even the principal investment. Anywhere between a small loss to a dramatic currency tail event loss is possible if not acted fast enough. Two complementary issues are examined. First one is to find out if there is an indicator that will signal the likelihood of the depreciation of the high interest rate currency (TRY) against the low interest currency (USD). REER is such an indicator signaling a possible depreciation whenever the value exceeds the important 100 level. The second part of the study focuses on the profitability of USD/TRY carry trade between 2005 and 2016 on a rolling months basis. The outcome as a whole shows positive results, but taken as two sample groups one sample covering 2005-2009, the other sample covering 2010-2016 the results are contradictory. First period is profitable while the second period produces a loss. Therefore the study concludes that USD/TRY as a carry trade is becoming increasingly less profitable despite the considerable interest rate difference between TRY and USD.
\end{abstract}

Keywords: carry trade, omega ratio, reer, minimum acceptable return

\section{Introduction}

Carry trade is a well-known and a simple method of taking advantage of interest rate differentials. Carry trade is basically borrowing (going short) in a low interest currency and investing (going long) in a high interest currency. The actual return from carry trade depends on the interest rate difference plus the appreciation/depreciation rates of both currencies. If the short currency depreciates against the long currency, the total return increases due to the fact that less short currency will be needed to cover the carry trade. The opposite is true if the short currency appreciates against the long currency. In this case, the return from the carry trade will be much less than the difference between interest rates.

In this regard carry trade is similar to directional position taking in currencies. The major difference is the targeted results. In carry trade method the target is to achieve a high return from a high interest currency. Currency risk is inherent. In directional position taking currency risk is the main risk factor and the currency appreciation/depreciation is the main target.

There have been numerous studies done on the concept of carry trades. A great number of the studies tried to answer the question of whether the currency rates are predictable. Predictability is important since if there is a slight chance of predictability then the possibility of a profitable carry trade becomes higher. Ca'Zorzi, Muck and Rubaszek (2015) found out that the preferred model for real exchange rates resembled the random walk in the short-run while it gradually approached Purchasing Power Parity (PPP) in the long-run. The study of Ince (2014) shows that using real-time data with panel estimation increases the predictability and the forecasting ability of the PPP model relative to single-equation estimation. In another study the econometric model used implied that close to the equilibrium the real exchange can be calculated using a random walk method. Especially at short horizons the random walk forecasts are successful. (Kilian and Taylor, 2003) One study found that implied volatilities seem to perform better for most forecasting horizons in terms of information content. (Andrade, Chang and Tabak, 2003) These studies try to improve the predictability of currency rates with varying levels of success. PPP long run predictability results confirm my research findings using a similar indicator called REER which can also be named as an early warning signal. 
A group of studies examined the risk factor in carry trades. Speculators invest in high interest currencies and currency crashes are linked to the sudden unwinding of these carry trades. (Brunnermeier, Nagel and Pedersen, 2008) From a meta-analysis of series of studies (Rogoff, 1996) inferred that in order to halve real exchange rate deviations from the mean, at least 3 to 5 years are needed.

When changes in interest rate expectations or volatility lead to an abrupt reversal of carry trades, high interest currencies depreciate and low interest currencies appreciate sharply. (Beranger et al., 1999) Price difference between two equivalently out-of-the-money options can be used as a risk indicator for carry trades. (Galati, Heath, McGuire, 2007) FX options can be used to hedge against a tail event that causes a huge drop in the value of the high interest rate currency. (Burnside, Kleshchelski and Rebelo, 2008) Even using options against a tail event have difficulties. At-the-money options protect more against a huge loss but are costly for hedging. Out-of-the-money options are cheaper but since they are far away from the present rates, they only protect against a large tail event but not against normal losses from carry trades.

A more recent method uses a binary choice of which currency to sell short and which to go long which in the long run help generate positive returns with moderate exposure and mildly positive skew. (Jorda, and Taylor, 2012) Second part of my research measured the profitability of the carry trades initiated in USD/TRY. Actual currency risks are used without trying to hedge them in order to show the real profitability. If the aim is to limit the currency risks then the above studies offer alternatives for lowering or eliminating the currency risks. One simple yet difficult way of avoiding currency risk is trying to time the carry trades. If the investor is capable of moving in and out of the markets fast enough, major currency risks as well as some profits might be avoided. For the rest of the investors who is in the market for a longer period that is not an option. In this case using options would be a better alternative. Further research is needed to find out the profitability of a carry trade using options. In such a study various option strike prices, option premiums and interest rate differentials have to be calculated for a result matrix.

Another research topic vis-a-vis carry trades has been new methods of position taking. One strategy goes long in a basket of foreign currencies and short in the dollar if the average foreign short-term interest rate is above the U.S. interest rate. When the average foreign short-term rate drops below the U.S. interest rate then long positions in the dollar are initiated. (Lustig, Roussanov and Verdelhan, 2014) Sorting currencies into portfolios based on net exports of finished goods or basic commodities generate a large spread in average excess returns. (Ready, Roussanov, Ward, 2013) These studies tried to enhance the returns from the carry trades by applying the portfolio management concept to carry trades. By spreading the risk among different currencies it is assumed that depreciation for instance in Brazilian Real might not be followed by depreciation in TRY or other high interest currencies. Alternatively we might assume that depreciation is unavoidable at certain times for all high interest rate currencies, yet the depreciation rates would be different therefore minimizing the damage by the average depreciation of all high interest rate currencies. Since the scope of my research was based on USD/TRY carry trades, the portfolio approach is not empirically tested. In order for this method to be less risky than a one currency pair carry trade, the correlation between different currency pairs have to be low.

The carry trade has four variables. First variable is the borrowing rate for the low interest (funding) currency. Second variable is the initial conversion rate from funding currency to the investment currency. Third variable is the return from the invested currency (T-Bill or government bond). Finally, the last variable is the conversion rate from the invested currency to funding currency. The first three variables are known at the start of the carry trade. The only unknown and the highest risk factor is the conversion rate at the end of the carry trade.

\section{Methodology}

In this study there will be two issues to be undertaken. The initial issue is whether we can define certain periods where initiating a carry trade will be most probably a losing trade. By using such a filter the investor might pick time periods where the probability of positive returns are higher. Is there such a filter? One indicator named Real Effective Exchange Rate (REER) published by the Central Bank of Turkey may contribute to this goal. It is different than Purchasing Power Parity (PPP) which empirically was shown to hold meaningful relationship with currency rates in the medium to long term. Nominal effective exchange rate is the weighted average value of the Turkish lira relative to the basket of the countries' currencies that have a significant share in Turkey's foreign trade.

Weights are determined using bilateral trade flows. As for real effective exchange rate, it is obtained by purifying relative price effects in nominal effective exchange rate.

REER can be used in two ways. One method will be to regress the REER against the USD/TRY rate. Since our aim is not to predict the USD/TRY rate, this method will not be analyzed further. Instead a no-trade zone if properly 
defined might eliminate some risky position taking. In trading there is a delicate balance between avoiding the losses and creating profits. If too many filters are used the losses might be lowered. At the same time some of the profitable trades can be missed altogether resulting in lower total profits. Imperfect though they may be, REERs have signaled large exchange rate overvaluations in the run-up to many financial crises, making it important for the IMF and others to monitor bilateral REERs and multilateral REERs. (Catao, 2007)

162 months of data was examined since January 2003. The hypothesis is to show that if REER is above 100 which indicates overvalued TRY against USD, then a correction will follow in the coming periods. Perfect timing is almost impossible, however a pre-warning suggesting not to initiate the carry trade can be generated. In certain cases it may take several months for REER to go down under the 100 level. The period under study had 17 warnings where in 16 of them a depreciation of TRY against USD followed in the coming month or took place within the next month and continued for additional months. From the perspective of risk control this method will minimize the risk. On the down side the method suggests to stay on the sidelines which will let the investor miss some of the profitable opportunities.

Table 1. Relationship between REER and TRY

\begin{tabular}{ccc}
\multicolumn{3}{l}{ depreciation against USD } \\
\hline $\begin{array}{c}\text { USD/TRY } \\
\text { Increase } \%\end{array}$ & $\begin{array}{c}\text { Period } \\
\text { \#Months }\end{array}$ & REER \\
7.01 & 1 & 91.65 \\
6.83 & 1 & 110.47 \\
13.88 & 2 & 110.98 \\
8.28 & 2 & 110.74 \\
19.32 & 2 & 118.90 \\
11.85 & 2 & 127.52 \\
33.02 & 4 & 118.73 \\
10.88 & 2 & 110.70 \\
6.77 & 2 & 121.44 \\
11.82 & 3 & 125.36 \\
22.26 & 5 & 112.85 \\
8.20 & 2 & 100.52 \\
13.37 & 5 & 112.46 \\
14.08 & 3 & 103.57 \\
8.87 & 4 & 104.12 \\
37.34 & 11 & 103,23 \\
5.36 & 1 & 101.68 \\
\hline
\end{tabular}

Source: Central Bank of Turkey, own calculations. 


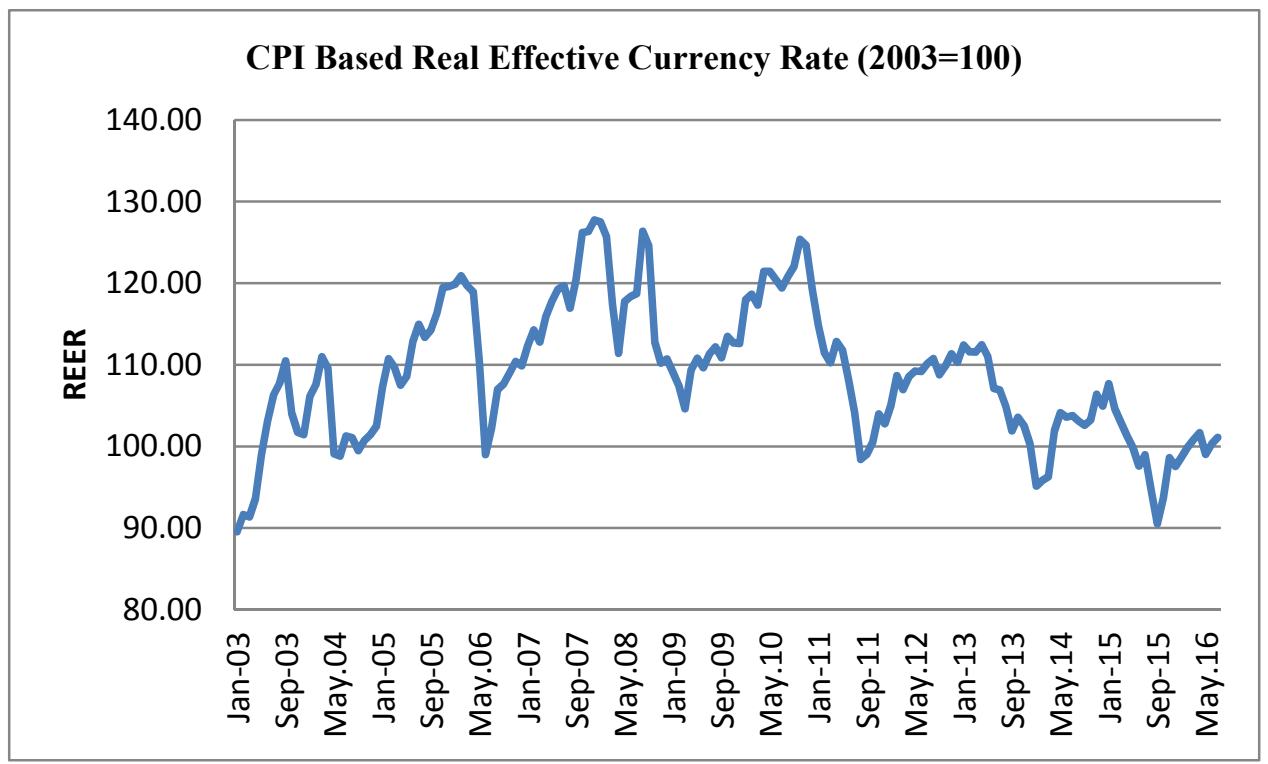

Figure 1. Most of the time REER is above 100. The window of opportunity is low.

The second issue is to calculate the profitability of a carry trade based on USD as the low interest currency and TRY as the high interest currency. To find the actual results of a carry trade some assumptions have to be made. First, for the borrowing rate 3 month libor rates plus 50 basis points were used. In the second step it was assumed that TRY was invested in a Bond Index. The return of the Government Domestic Debt Instruments is calculated by using BIST-KYD GDS ALL Index under BIST-KYD GDS Indices, which is published by Borsa Istanbul. This index reflects the yield of zero coupon and fixed-rate coupon Turkish Government Debt Securities (GDS), which are traded in Debt Securities Market, by covering all maturity bands.

Finally, the carry trade returns were calculated on a 12 month rolling basis. In an actual trade the investor might initiate and close the trade at any given interval. For empirical purposes we assumed that any period less than one year should not be desirable unless the adverse conditions forces the investor to limit the currency risk therefore to close the carry trade position. Based on the above assumptions the carry trade returns were calculated starting from 2005 until the end of August 2016.

The profitability of the rolling returns will be calculated using the Omega ratio. The Omega ratio is calculated by including all the returns above and below a certain threshold which is also called Minimum Acceptable Return (MAR). (Keating and Shadwick, 2002) It is also considered to be a probability-weighted ratio of gains to losses relative to the MAR. Every investor's MAR could be different which suggests that every investor will generate their own Omega Ratio. If the ratio is " 1.00 " for a given MAR it is concluded that the MAR target is achieved but no additional return is generated.

\section{Results}

The Omega ratio rate for the total period between January 2005 and August 2016 with a MAR of $10 \%$ is 0.306 . (It covers 128 months of data). This can also be stated as $10 \%$ MAR not being achieved. Restating that, it is safe to say that the probability of achieving a MAR of $\% 10$ is extremely low for the coming years. The Omega ratio approaches 0.643 at 5\% MAR level. Even a 5\% MAR level is not achievable. At 2\% MAR the Omega ratio reaches the " 1 " level. Is it viable to take the currency risk for $2 \%$ ? Considering the risks, it is not an attractive rate of return for a carry trade. In the past much higher returns were realized when the Turkish interest rates were above $20 \%$ levels.. The period chosen for performance measurement needs delicate balancing between a large enough sample size for statistical robustness and the trend of the performance. Regardless of using a Sharpe ratio, Sortino ratio . Omega ratio or any other performance measure, the performance of the investment might be in an uptrend, downtrend or flat. For instance 10 year data would show an acceptable Sharpe ratio despite a dismal return in the last couple of years. 


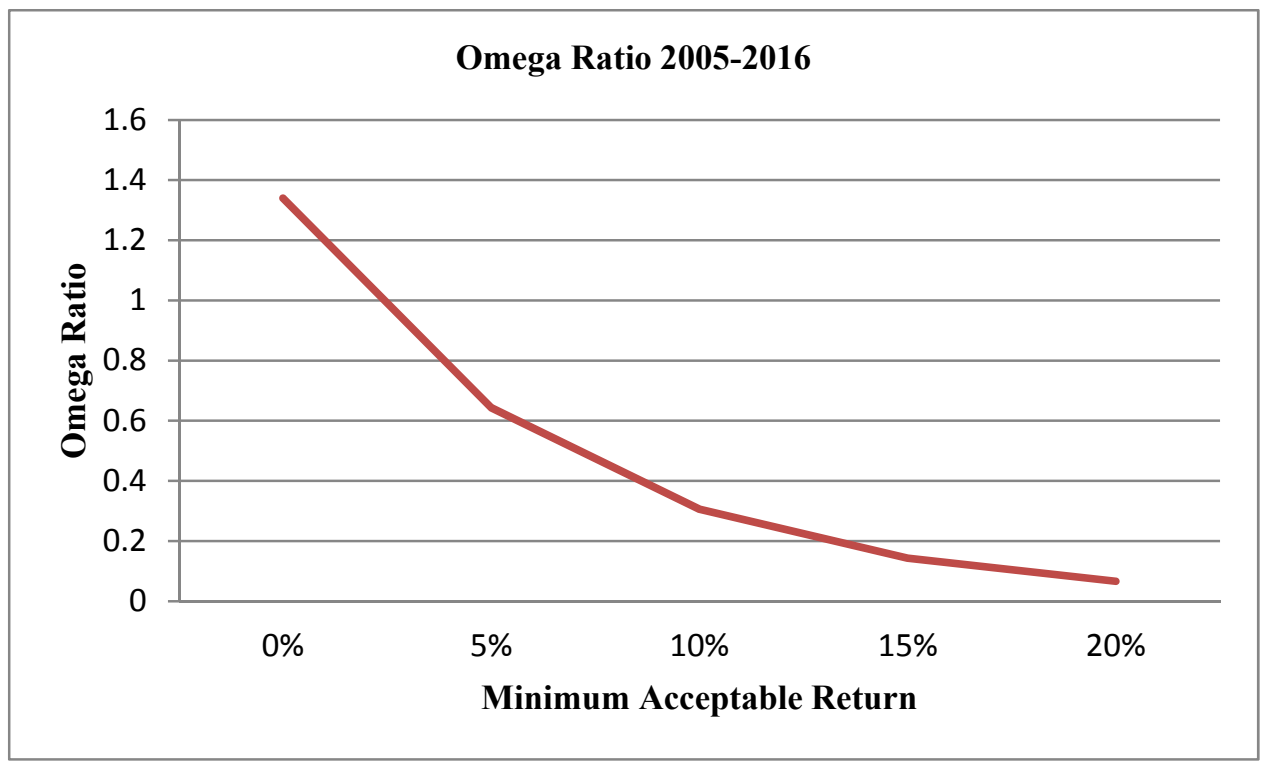

Figure 2. Omega ratio is at 1.00 level at 5\% MAR and at 0 level at 21\% MAR

Using this concept the sample data were split into 2005-09 period and 2010-2016 period. A fund may have a very high above return in one period, and then might have several below returns. The Omega ratio does not differentiate on the timing of above or below returns. Recalculating the Omega ratio for two sets of data the results appear to be dramatically different. At $10 \%$ MAR for the first period Omega ratio is 1.07 where in the second period this ratio drops to 0.035 . In the first period the carry trade was able to generate a return of $10 \%$. In the second period, the ratio of 0.03 suggesting that returns were far below the \%10 MAR. The situation gets more dramatic if we use $\% 5$ MAR as our threshold level. This time for the first period the Omega ratio jumps 2.23 , for the second period it barely increases to 0.121 . Again in the first period the $\% 5$ MAR is easily achieved, in the second period 5\% MAR is still not matched. If we lower the threshold level to $0 \%$ return which is actually a breakeven level for the periods considered, then for the first period the Omega ratio rises to 4.82. This gives us a very high probability of achieving a breakeven level. For the second period the Omega ratio is only 0.35 giving a low probability of even matching the breakeven level. For the last period carry trades in USD/TRY would be a losing proposition.

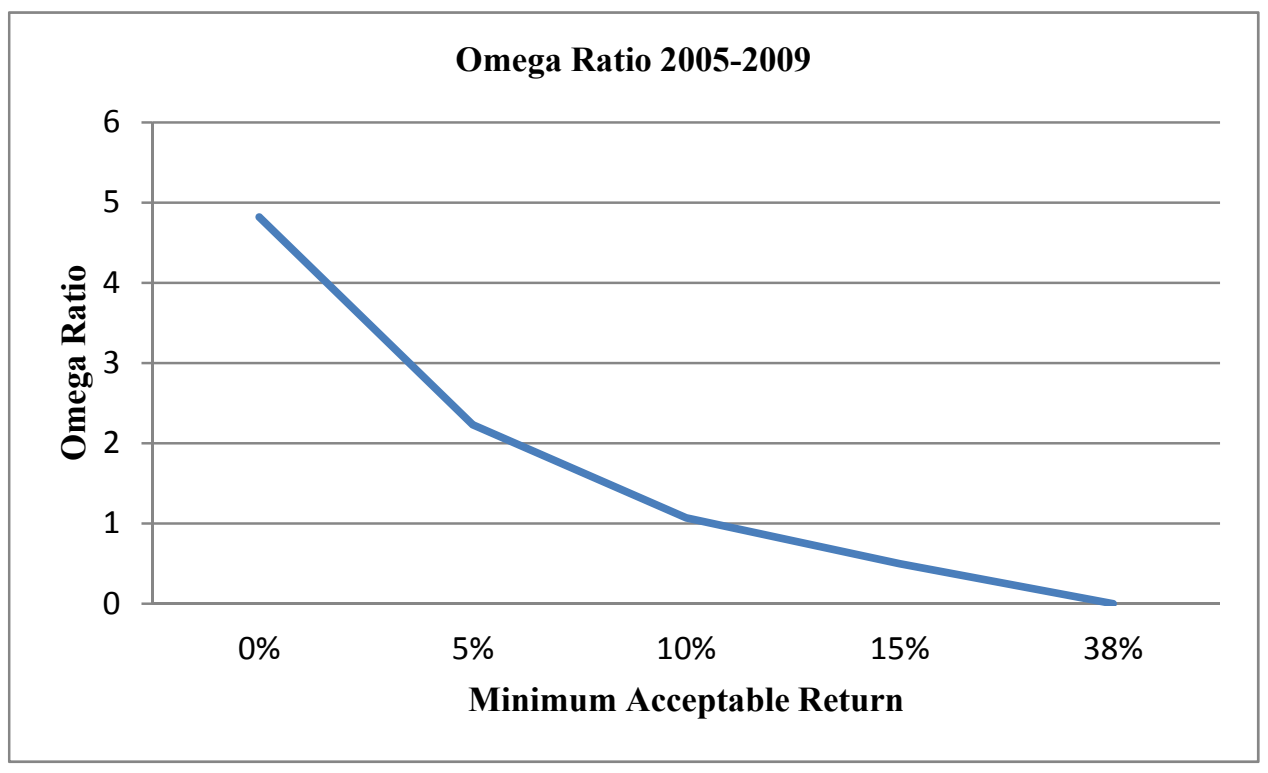

Figure 3. Omega ratio easily meets 1.00 level at $10 \% \mathrm{MA}$ 


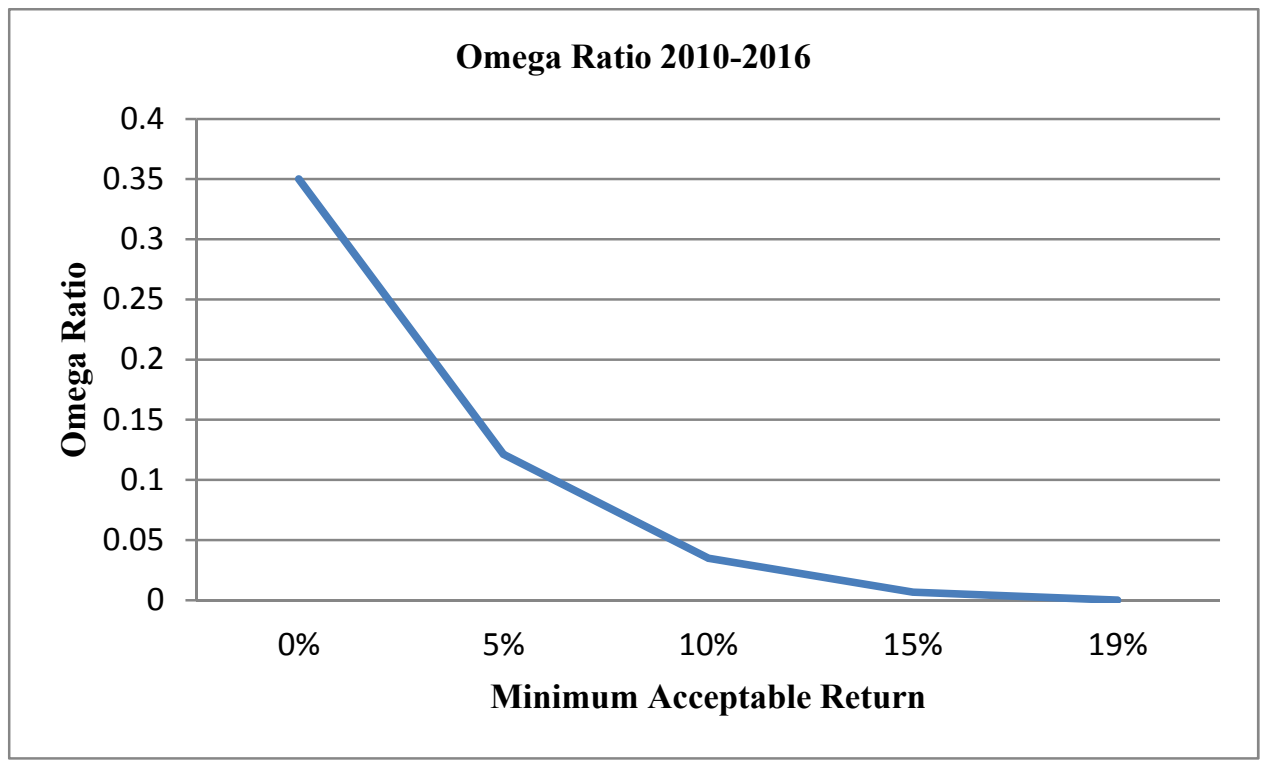

Figure 4. Omega ratio cannot even reach the breakeven level

Is it possible to not make profit from a carry trade even the interest rate differential between two currencies are high? Omega ratio analysis clarifies the reason for this anomaly. Currency volatilities and specifically high depreciation rates repeating itself throughout the years diminishes the profitability of carry trades. A depreciation chart might also give us a different perspective.

Table 2. USD/TRY depreciation between 2005-August 2016

\begin{tabular}{llc}
\hline Year & USD/TRY Rate & Change USD/TRY \\
\hline 2005 & 1.3483 & $0.42 \%$ \\
\hline 2006 & 1.4124 & $4.75 \%$ \\
\hline 2007 & 1.1649 & $(17.50) \%$ \\
\hline 2008 & 1.5291 & $31.30 \%$ \\
\hline 2009 & 1.4945 & $2.30 \%$ \\
\hline 2010 & 1.5450 & $3.40 \%$ \\
\hline 2011 & 1.8980 & $22.80 \%$ \\
\hline 2012 & 1.7862 & $(5.90) \%$ \\
\hline 2013 & 2.1343 & $19.50 \%$ \\
\hline 2014 & 2.3311 & $9.2 \%$ \\
\hline 2015 & 2.9233 & $25.4 \%$ \\
\hline 2016 (Aug) & 2.9597 & $1.20 \%$ \\
\hline
\end{tabular}

Source: Central Bank of Turkey, www.tcmb.gov.tr

Between 2005 and 2009, in only one year the depreciation is very high. In 2006, the carry trade would be slightly profitable, and in 2008 the carry trade would be a disaster. Between 2010 and 2016, out of 7 periods 4 of them had high rates of depreciation. This is why despite the high interest rate differential the carry trades became increasingly difficult to profit. 


\section{Conclusion}

In this study we tried to find a filter which would issue a pre-warning before the depreciation of the high interest currency (TRY) against the low interest currency (USD). By using this filter the aim was to avoid currency losses during a carry trade. Actually by using an indicator called REER there was conclusive evidence that it was a strong possibility to avoid the currency losses. Before any major TRY depreciation except one case the REER was always above the 100 level. Unfortunately, it is not possible to use it as an entry-exit indicator for carry trades. The main reason is the tendency of the REER to stay in the overvalued zone (Above 100) for long periods of time. Between Jan-2013 and August-2016, there are 163 months and out of those months the REER is at the overbought level for 139 months. Basically, the indicator keeps you out of the carry trade for most of the period, which classifies it as a very high risk-averse indicator.

In the second part of the study a carry trade is simulated with rolling months. The period covered was between 2005 and August of 2016. Omega ratio was used for measuring the performance of the carry trades. Initially, using a $\% 10$ MAR, it was obvious that the achievement of the target had a very low probability. Recalculating at $2 \%$ MAR, the Omega ratio reached the " 1.00 " level. For the period considered $2 \%$ carry trade profit was possible. Splitting the sample size into 2 periods, one between 2005-2009 and the other 2010-2016, Omega ratios was recalculated for \%10 MAR and all the increments till $0 \%$ MAR. The outcome was not evenly distributed. The first period was able to meet the $\% 10$ MAR level, therefore a minimum of $10 \%$ carry trade return.. Quite contrary compared to the first period, the second period could meet neither the \%10 return nor \%5 return. Actually the results suggested that between 2010-2016 the carry trades were generating losses.

\section{References}

Andrade, S.C., Chang, E.J., \& Tabak, B.M. (2003). Tracking Brazilian exchange rate volatility. Economic Society 2004 Far Eastern Meetings, Econometric Society, 487.

Beranger, F., Galati, G., Tsatsaronis, K., Kleist, K von. 1999. The yen trade and recent foreign exchange volatility. BIS Quarterly Review, March, 33-7.

Brunnermeier, M., Nagel, S., \& Pedersen, L. (2008). Carry Trades and Currency Crashes. NBER Working Paper 14473.

Burnside, A.C., Eichenbaum, M., Kleshchelski, I., \& Rebelo, S. (2008). Do peso problems explain the returns to the carry trade? NBER Working Papers 14054.

Ca'Zorzi, M., Muck, J., \& Rubaszek, M. (2015). This time the random walk loses. Retrieved from http://voxeu.org/article/time-random-walk-loses

Catao, A.V. (2007). Why real exchange rates?. Finance and Development, September. 46-47.

Galati, G., Heath, A., \& McGuire, P. (2007). Evidence of carry trade activity. BIS Quarterly Review, September. 27-41.

Ince, O. (2014). Forecasting exchange rates out-of-sample with panel methods and real-time data. Journal of International Money and Finance, 43(C), 1-43.

Jorda, O., \& Taylor, A.M. (2012). The carry trade and fundamentals: Nothing to fear but FEER itself. Journal of International Economics, 88, 74-90.

Keating, C., \& Shedwick, W.F. (2002). A universal performance measure. The Finance Development Centre. London.

Kilian, L., \& Taylor, M.P. (2003). Why is it so difficult to beat the random walk forecast of exchange rates? Journal of International Economics, 60, 85-107.

Lustig, H., Roussanov, N., \& Verdelhan, A. (2014). Countercyclical currency risk premia. Journal of Financial Economics, 111, 527-553.

Ready, R., Roussanov, N., \& Ward, C. (2013). Commodity trade and the carry trade: A tale of two countries. NBER Working Paper 10371.

Rogoff, K. (1996). The purchasing power parity puzzle. Journal of Economic Literature 34, 647-668. 